\title{
The effect of Chinese EFL students' learning motivation on learning outcomes within a blended learning environment
}

\author{
Renzhong Peng, Rongrong Fu \\ Huazhong University of Science and Technology, China
}

\begin{abstract}
The purpose of this study was to explore the relationship between Chinese English as a foreign language (EFL) students' learning motivation and learning outcomes in a blended learning environment. A questionnaire was administered to 960 EFL students, and 10 of them participated in an interview. Following a series of analyses on the data collected through the questionnaire, consisting of exploratory factor analysis, reliability analysis, descriptive analysis, and correlation analysis, a structural relationship model that integrated learning motivation and learning outcomes was developed and tested. The results reveal that both intrinsic motivation and extrinsic motivation have a positive relationship with learning outcomes within a blended learning environment, both of which are conducive to improving students' English linguistic competence and facilitating their psychological development of English learning. Moreover, intrinsic motivation is more important than extrinsic motivation. In intrinsic motivation, intrinsic interest in English and the intrinsic goal of understanding English culture are the two most important motives. Based on these results, implications and recommendations for future research are provided.
\end{abstract}

Implications for practice or policy:

- Foreign language educators should consider the stimulation of students' learning motivation as the main task in blended courses.

- Foreign language educators should pay more attention to the development of students' intrinsic motivation than extrinsic motivation to produce more favourable learning outcomes in blended courses.

- Foreign language educators should focus on developing students' intrinsic interest in foreign language and culture in terms of the cultivation of students' intrinsic motivation in blended courses.

Keywords: blended learning, English as a foreign language (EFL), learning motivation, learning outcomes, structural equation modelling

\section{Introduction}

The increasing development of new information and communication technology brings along great opportunities and changes in the field of education, and traditional face-to-face learning has been challenged by online learning that can provide abundant learning materials, accommodate student population diversity and meet students' varying needs (Ma \& Zhang, 2011; Wu, 2013). However, online learning has its disadvantages in terms of insufficient peer contact and social interaction and thus cannot replace traditional classroom instruction (J. W. Wu et al., 2010). In order to address the limitations from traditional classroom instruction or online learning, it is necessary to combine them (Ituma, 2011). The synthesis of traditional classroom instruction and online learning gives rise to the conceptualisation of blended learning, which offers a new way of course content production, delivery and instruction. Studies have examined students' and teachers' perceptions of blended learning and revealed the positive effect of blended learning on students' learning achievement (Akgündüz \& Akınoğlu, 2017; Jia et al., 2012; Pereira et al., 2007; Pinto-Llorente et al., 2017; Tosun, 2015; Wichadee, 2017; L. F. Wu, 2013). Particularly, scholars in China have shown much concern about how to integrate blended learning into language courses (He, 2004; Ma \& Zhang, 2011) and have investigated the influence of blended learning on students' learning outcomes (Suo \& Chi, 2018; H. R. Zhang et al., 2018; Y. L. Zhang, 2013; Y. Y. Zheng, 2019). But there is a lack of research to examine specific variables that may affect students' learning outcomes within a blended learning environment. Thus, it is necessary to consider the roles of the learner and technical and instructional factors, such as learning motivation, which is one of the most important learner factors influencing learning outcomes. This study attempted to investigate the relationship between Chinese English as a foreign language (EFL) students' learning motivation and learning outcomes within a blended 
learning environment by applying structural equation modelling, which provides insights into how different types of learning motivation influence learning outcomes and promote effective English language learning.

\section{Literature review}

Blended learning is an integrative way of learning, involving traditional face-to-face learning and distributed learning (Graham, 2012). Some scholars have reached a consensus on defining blended learning as a thoughtful integration of traditional classroom face-to-face instruction with computer technology-based learning, converging the strength of synchronous and asynchronous learning (Garrison \& Kanuka, 2004; Shams, 2013; So \& Brush, 2008; Vanslambrouck et al., 2018; Wichadee, 2017). Moreover, scholars such as Lim and Morris (2009) and J. H. Wu et al. (2010) have described it as a learning approach combining different instructional delivery methods and styles of learning, such as videotape, web-based training, electronic performance support system and classroom teaching. In this study, blended learning is regarded as a special teaching or learning model that supplements synchronous face-to-face instruction in the classroom with synchronous or asynchronous online learning supported by Internet technology (Garrison \& Kanuka, 2004; Graham, 2012; He, 2004; Lim \& Morris, 2009; Ma \& Zhang, 2011; So \& Brush, 2008).

The concept of blended learning has received great attention from researchers and educators for its improved pedagogy and increased access and cost-effectiveness (Graham, 2012). By investigating students' and instructors' perceptions and attitudes towards blended learning, Kofar (2006), Tosun (2015) and L. F. $\mathrm{Wu}$ (2013) have pointed out that both students and instructors support this learning model. The blended learning model can be incorporated into different courses in various ways, including the utilisation of online courses, social learning platforms and social media (e. g., small private open courses, massive open online courses [MOOCs], Edmodo, Facebook, Skype). For example, Jia et al. (2012) built an individual vocabulary acquisition and assessment system by using the course management system Moodle and integrated it into regular English instruction; Shih (2011) designed a blended English writing course by combining Facebook with college English writing classroom instruction. The integration of a blended learning model into traditional language teaching has proven to be effective in increasing students' language proficiency, such as speaking, writing, listening and reading (Lungu, 2013; Obari \& Lambacher, 2014; Shams, 2013; Shih, 2011; Wichadee, 2017; Y. Y. Zheng, 2019), and enhancing students' learning motivation, learning autonomy and satisfaction, as well as confidence, enthusiasm and responsibility for learning (Jia et al., 2012; Pinto-Llorente et al., 2017; Shams, 2013; Shih, 2011; Wang et al., 2009). Additionally, some factors relating to learner characteristics and instruction, such as learning motivation and content feature, may affect students' satisfaction and performance in blended learning (Lim \& Morris, 2009; J. H. Wu et al., 2010).

Learning motivation, as one of the most significant components of learning in any environment, is an important factor affecting learning outcomes in a blended learning environment (Firat et al., 2018; Lim \& Morris, 2009; Shih, 2011; Yusoff et al., 2017). The literature on learning motivation shows that motivation has different categories. For example, Gardner (1985) distinguishes between integrative motivation, which is based on learners' desire for successful communication and integration into the target culture, and instrumental motivation, which emphasises the utilitarian and pragmatic reason for learning a language. Moreover, Crookes and Schmidt (1991) proposed that the classification of motivation into intrinsic motivation and extrinsic motivation may apply to language learning. Students with intrinsic motivation participate in learning activities for reasons such as curiosity and challenge, whereas students with extrinsic motivation participate for external motivating factors such as grades and rewards (Hsieh, 2014). Similarly, Ryan and Deci (2020) assume intrinsic motivation is the active integrative tendency, which is based on interest and curiosity and leads to satisfaction and joy, while extrinsic motivation concerns actions performed for reasons other than inherent satisfaction. And the four subtypes of extrinsic motivation in Deci and Ryan's $(2008,2012)$ self-determination theory (SDT) consists of external regulation, introjected regulation, identified regulation and integrated regulation (Deci \& Ryan, 2012; Ryan \& Deci, 2020). Intrinsic motivation and extrinsic motivation are not dichotomous; instead, extrinsic motivation may be internalised and autonomous, and extrinsically motivated behaviours can have an influence on intrinsic motivation by satisfying autonomy, competence and relatedness needs (Deci \& Ryan, 2012; Ryan \& Deci, 2020). According to SDT, motivation includes autonomous motivation and controlled motivation; autonomous motivation involves both intrinsic motivation and the types of extrinsic motivation (identified regulation and integrated regulation) in which people recognise the value of an activity and integrate it into their sense of self; controlled motivation comprises both external regulation (reward, punishment) and 
introjected regulation (avoidance of shame, approval motive) in which people suffer from pressure and anxiety (Deci \& Ryan, 2008, 2012; Ryan \& Deci, 2020).

By synthesising those views on motivation, this study assumes that learning motivation consists of intrinsic motivation and extrinsic motivation, which can be defined as follows: intrinsic motivation is associated with both integrative tendencies and the types of instrumental tendencies that are autonomous and selfdetermined and enable people to acquire pleasure and satisfaction from the activity they are engaged in; extrinsic motivation concerns actions performed for external factors as grades and rewards rather than for interest and joy, which may bring people pressure and stress (Deci \& Ryan, 2008, 2012; Gardner 1985; Hsieh, 2014; Ryan \& Deci, 2020).

Studies on learning motivation have discussed the internal structure of learning motivation, investigated the level of students' learning motivation and the relationship between learning motivation and factors such as gender and geographical regions and explored how learning motivation influences academic achievements in traditional learning environments (Carreira, 2011; Csizér \& Dörnyei, 2005; Saito et al., 2016; Tokan \& Imakulata, 2019; Vansteenkiste et al., 2004; Yang, 2018). However, with the prevalence of Internet technology, more attention has been paid to learning motivation in e-learning environments. For example, Chen and Jang (2010), Ciampa (2014), Firat et al. (2018) and Yilmaz (2017) investigated level of learning motivation and motivating factors of students across the age range within an online or mobile learning environment. Moreover, some feasible strategies for enhancing learning motivation have been explored in technology-supported learning settings, such as project-based digital storytelling using an online information-searching system and Microsoft's Photo Story (Hung et al., 2012), ubiquitous games (Liu \& Chu, 2010) and mobile gamification learning (Su \& Cheng, 2014). In addition, the impact of learning motivation on learning outcomes in e-learning environments has been empirically examined (Law et al., 2010; Lim \& Kim, 2003). However, it remains unclear how different types of learning motivation affect learning outcomes within a blended learning environment, and there is a lack of research probing the relationship between learning motivation and learning outcomes in blended learning settings. Therefore, this study attempted to explore the effect of EFL students' learning motivation on learning outcomes within a Chinese blended learning context. The research questions of this study were as follows:

- What is the Chinese EFL students' main learning motivation in a blended learning environment?

- What are the Chinese EFL students' learning outcomes in a blended learning environment?

- How does the Chinese EFL students' learning motivation affect learning outcomes in a blended learning environment?

\section{Methods}

\section{Participants}

For the study, we randomly chose 960 students (461 males and 499 females) of College English from six universities across China. They were from six departments: Materials Engineering and Science, Resources and Environmental Engineering, Computer and Technology, Management, Philosophy and History. Among those participants, 10 students (referred to as A, B, C, D, E, F, G, H, I and J to preserve anonymity) were chosen to be interviewed. Before the questionnaire and student interviews, the participants were informed of the purpose of the study and that the results of data collection would be intended solely for academic purposes. They volunteered to complete the questionnaire and to be interviewed.

The participants had experienced blended learning in the process of English learning by receiving classroom instruction and undertaking web-based learning. On the one hand, they attended classroom instruction twice a week. On the other hand, they participated in Internet-based English learning outside the classroom by utilising different online resources and delivery methods, mainly English learning platforms (New Horizon College English Learning Platform), online courses (MOOCs, NetEase Online Open Courses) and social media applications (Youdao Dictionary, Wechat and BaiCizhan).

\section{Instruments}

We constructed a questionnaire in Chinese for investigating Chinese EFL students' learning motivation and learning outcomes in a blended learning environment. The questionnaire consisted of two parts: The first 
part related to demographic information (schools, majors, genders), and the second part consisted of 23 descriptive items (finally revised into 20 items) on learning motivation and learning outcomes within a blended learning environment. Before deciding on the items of learning motivation in the questionnaire, we asked students in interviews, "What is your motivation for learning English in a blended learning environment?" We summarised and categorised the responses by the key words they mentioned, from which we identified two main motivational characteristics by analysing students' motivation (Table 1):

- Students' English learning motivation mainly concerned their attitudes and goals for learning English.

- Students' goals for learning English were mainly integrative (e.g., learning English culture, communicating with foreigners) and instrumental (e.g., becoming more knowledgeable, finding jobs).

Table 1

Motivation profiles of the interviewees

\begin{tabular}{lcl}
\hline Motivation & No. of interviewees & Interviewees \\
\hline $\begin{array}{l}\text { Going abroad (studying abroad, travelling around } \\
\text { the world) }\end{array}$ & 4 & Students A, C, D, J \\
$\begin{array}{l}\text { Learning English culture } \\
\text { Curriculum requirements } \\
\text { (passing exams, completing learning tasks) }\end{array}$ & 4 & Students A, C, G, H \\
Getting good grades & 3 & Students B, D, E \\
Finding jobs & 1 & \\
Interest in English & 7 & Student F \\
Communicating with foreigners & 2 & Students B, D, E, F, G, I, J \\
Becoming more educated and knowledgeable & 1 & Students C, H \\
\hline
\end{tabular}

Thus, we referred to Gardner's (1985) Attitude/Motivation Test Battery (AMTB), which contains various sub-tests and can be used in different forms for varying purposes. According to the students' responses in the interview, students' English learning motivation mainly involved interest in foreign languages, attitudes towards language learning and integrative and instrumental orientation in AMTB; thus, the corresponding sub-tests were used for reference and modified for the Chinese university context. As a result, we designed a set of nine items to assess motivational traits in relation with interest in English, attitudes towards learning English and integrative orientation and instrumental orientation of learning English (see Table 2).

Table 2

Items of learning motivation section

\begin{tabular}{ll}
\hline Item & Content \\
\hline Interest in English & I have interest in English. \\
Attitudes towards learning English & It is imperative to complete English curriculum task. \\
& It is important to get good grades in English course. \\
Integrative orientation & I learn English to socialise with foreigners. \\
& I learn English to understand and appreciate English culture. \\
Instrumental orientation & I learn English for it will help me broaden my horizon and \\
& develop myself. \\
& I learn English for it will help me find a better job. \\
& I learn English because I plan to study abroad. \\
& I learn English because I plan to travel abroad. \\
\hline
\end{tabular}

The design of items on learning outcomes is grounded on research on the effectiveness of blended learning in improving students' foreign language proficiency, such as speaking, writing, reading, writing and vocabulary, and facilitating their psychological development, such as enhancing their learning autonomy, confidence, responsibility, enthusiasm and satisfaction (Jia et al., 2012; López-Pérez et al., 2011; Obari \& Lambacher, 2014; Pinto-Llorente et al., 2017; Shams, 2013; Shih, 2011; Wang et al., 2009; Wichadee, 2017; H. R. Zhang et al., 2018; Y. Y. Zheng, 2019). Written in Chinese, the questionnaire adopts a 5-point Likert scale ranging from 1 (totally disagree) to 5 (totally agree). 


\section{Data collection and analysis}

Two types of data were collected from the questionnaire and interview in this study. The questionnaire was distributed to 960 students during the class break. Among them, 878 responses $(91.5 \%)$ were valid. It took participants approximately eight minutes to complete the questionnaire. The data collected through the questionnaire were analysed with SPSS version 19 and AMOS version 19. Firstly, exploratory factor analysis (EFA) was performed to extract the main factors and remove items that did not meet the requirements for factor extraction. Secondly, reliability analysis was conducted to test the internal consistency of the revised questionnaire. And a revised 20-item questionnaire was constructed. Thirdly, descriptive analysis and correlation analysis were applied. Finally, structural equation modelling was employed to explore the relationship between the students' learning motivation and learning outcomes in blended learning.

Ten students were randomly selected to be interviewed, and their responses to five interview questions were recorded and analysed. By eliciting the students' responses, the interview served two purposes: questionnaire design and interpretation of data results of the questionnaire. The interview questions were:

- What do you think of blended learning?

- How do you learn English in a blended learning environment?

- What methods do you often use to learn English outside the classroom and why do you use those methods?

- What is your motivation for learning English?

- What effects does blended learning have on your English learning?

\section{Results}

\section{EFA and reliability analysis}

To conduct factor extraction and examine the internal structure of the original 23-item questionnaire of the students' learning motivation and learning outcomes in blended learning, the first EFA was performed with principal component analysis and varimax orthogonal rotation, which converged after seven times of iteration rotation. The results showed that the Kaiser-Meyer-Olkin (KMO) statistic obtained was $0.874>$ 0.7 and Bartlett's test of sphericity was significant $\left(\mathrm{x}^{2}=9706.106, d f=378, p=.000<0.001\right)$, indicating the sample size and data collection met the requirements for factor analysis. Likewise, the second EFA was conducted, and three descriptive items of learning outcomes were removed for low factor loading or crossloading. The results showed $\mathrm{KMO}=0.858>0.7$, and Bartlett's test of sphericity was significant $\left(\mathrm{x}^{2}=\right.$ $7337.475, d f=190, p=.000<0.001)$. Through orthogonal rotation, which converged after five times of iteration rotation, four latent factors were extracted by adopting eigenvalue greater than 1.0 and factor loading greater than 0.40 .

After the EFA, a revised questionnaire was constructed with 20 descriptive items which fell into four factors (see Table 3). Firstly, there were six items of learning motivation loading on Factor 1, which represents intrinsic learning motivation (LM_1), that is autonomous and self-determined and related with interest, curiosity, pleasure and satisfaction. Among these six items, the first three items "having interest in English" $(\operatorname{lm} 1)$, "understanding English culture" ( $\operatorname{lm} 2)$, "socialising with foreigners $(\operatorname{lm} 3)$ " are motives based on students' intrinsic interest, curiosity and integrative orientation; the other three items, "broadening my horizon and developing myself" ( $\operatorname{lm} 4)$, "studying abroad" $(\operatorname{lm} 8)$ and "travelling abroad" ( $\operatorname{lm} 9)$, concern motives which are autonomous, satisfy students' autonomy and competence needs, and bring students pleasure, though they are related to instrumental orientation in Gardner's (1985) AMTB. Secondly, Factor 2 representing extrinsic learning motivation (LM_2) consisted of three items on learning motivation ( $\operatorname{lm} 5$, $\operatorname{lm} 6, \operatorname{lm} 7$ ), which concern behaviours performed for external reasons (curriculum tasks, grades, job) and which cause students anxiety and pressure. Thirdly, the five items of learning outcomes (lo1-lo5) load on Factor 3, which is called improvement in English linguistic competence (LO_1) and indicates the positive effect of blended learning on students' English linguistic competence (e.g., speaking, writing, listening, reading). Finally, there are six items of learning outcomes (lo7-lo12) loading on Factor 4, which is named psychological development of English learning (LO_2) and closely relates to students' psychological development (e.g., confidence, autonomy, perseverance, satisfaction) in blended learning. The items' loading value, eigenvalue of factors and variance explanatory rate are shown in Table 3 . The extraction of 
four factors for the questionnaire accounts for $56.385 \%$ of the variance, and the factor loadings of 20 descriptive items range from 0.478 to 0.897 .

Table 3

EFA results

\begin{tabular}{lccc}
\hline Items & Factor loading & Eigenvalue & Variance \% \\
\hline Intrinsic learning motivation (LM_1) & & 2.944 & 14.718 \\
\hline lm1 Having interest in English & 0.527 & & \\
lm2 Understanding English culture & 0.660 & & \\
lm3 Socialising with foreigners & 0.734 & & \\
lm4 Broadening my horizon and developing myself & 0.653 & & \\
lm8 Studying abroad & 0.699 & & \\
lm9 Travelling abroad & 0.697 & & \\
\hline Extrinsic learning motivation (LM_2) & & & \\
\hline lm5 Completing English curriculum task & 0.852 & \\
lm6 Getting good grades & 0.897 & \\
lm7 Finding a better job & 0.756 & & \\
\hline Improvement in English linguistic competence (LO_1) & & & \\
\hline lo1 Improving my English speaking skills & 0.760 & \\
lo2 Improving my English listening skills & 0.767 & & \\
lo3 Improving my English writing skills & 0.654 & & \\
lo4 Improving my English reading skills & 0.706 & \\
lo5 Improving my English vocabulary & 0.478 & & \\
\hline Psychological development of English learning (LO_2) & & & \\
\hline lo7 Increasing my autonomy in English learning & 0.710 & \\
lo8 Increasing my confidence in English learning & 0.739 & \\
lo9 Increasing my perseverance in English learning & 0.788 & \\
lo10 Increasing my enthusiasm for English learning & 0.785 & \\
lo11 Increasing my responsibility for English learning & 0.539 & \\
lo12 Increasing my English learning satisfaction & 0.503 & & \\
\hline
\end{tabular}

Table 4

Reliability analysis results

\begin{tabular}{lc}
\hline Factors & Cronbach's $a$ \\
\hline Intrinsic learning motivation (LM_1) & 0.784 \\
Extrinsic learning motivation (LM_2) & 0.814 \\
Improvement in English linguistic competence (LO_1) & 0.767 \\
Psychological development of English learning (LO_2) & 0.829 \\
\hline Total & 0.855 \\
\hline
\end{tabular}

Reliability analysis was conducted by Cronbach's alpha to examine the internal consistency of the revised 20-item questionnaire. As can be seen from Table 4, the Cronbach's alpha values for the four extracted factors range from 0.767 to 0.829 , greater than the threshold value of 0.7 . The results suggest that the questionnaire has adequate reliability measuring the latent variables.

\section{Descriptive statistics and correlations}

Table 5 presents results of descriptive analysis of learning motivation and learning outcomes. As can be seen, for items measuring students' learning motivation, the mean values of extrinsic motivation descriptive items are greater than that of intrinsic motivation items, indicating that students' extrinsic motivation for learning English within the context of blended learning is stronger than their intrinsic motivation. Among these items, "finding a better job" (mean = 4.09) is the strongest motive for learning English in a blended learning environment. For items assessing students' learning outcomes, the mean values of all items are above 3.5. Among these items, the mean value of the item "improving my English vocabulary" (4.05) is the highest. 
Table 5

Descriptive statistics of learning motivation and learning outcomes in blended learning

\begin{tabular}{|c|c|c|c|c|}
\hline Items & Minimum & Maximum & Mean & SD \\
\hline \multicolumn{5}{|l|}{ Intrinsic learning motivation (LM_1) } \\
\hline lm1 Having interest in English & 1 & 5 & 3.45 & 0.99 \\
\hline $\operatorname{lm} 2$ Understanding English culture & 1 & 5 & 3.39 & 0.93 \\
\hline $\operatorname{lm} 3$ Socialising with foreigners & 1 & 5 & 3.75 & 0.84 \\
\hline $\operatorname{lm} 4$ Broadening my horizon and developing myself & 1 & 5 & 3.93 & 0.75 \\
\hline lm8 Studying abroad & 1 & 5 & 3.35 & 0.95 \\
\hline $\operatorname{lm} 9$ Travelling abroad & 1 & 5 & 3.69 & 0.86 \\
\hline \multicolumn{5}{|l|}{ Extrinsic learning motivation (LM_2) } \\
\hline Im5 Completing English curriculum tasks & 1 & 5 & 3.95 & 0.85 \\
\hline lm6 Getting good grades & 1 & 5 & 4.02 & 0.78 \\
\hline $\operatorname{lm} 7$ Finding a better job & 1 & 5 & 4.09 & 0.72 \\
\hline \multicolumn{5}{|l|}{ Improvement in English linguistic competence (LO_1) } \\
\hline lo1 Improving my English speaking skills & 1 & 5 & 3.71 & 0.70 \\
\hline lo2 Improving my English listening skills & 1 & 5 & 3.89 & 0.61 \\
\hline lo3 Improving my English writing skills & 1 & 5 & 3.50 & 0.75 \\
\hline lo4 Improving my English reading skills & 1 & 5 & 3.80 & 0.68 \\
\hline lo5 Improving my English vocabulary & 1 & 5 & 4.05 & 0.57 \\
\hline \multicolumn{5}{|l|}{ Psychological development of English learning (LO_2) } \\
\hline lo7 Increasing my autonomy in English learning & 1 & 5 & 3.52 & 0.86 \\
\hline lo8 Increasing my confidence in English learning & 1 & 5 & 3.51 & 0.79 \\
\hline lo9 Increasing my perseverance in English learning & 1 & 5 & 3.57 & 0.82 \\
\hline lo10 Increasing my enthusiasm for English learning & 1 & 5 & 3.65 & 0.78 \\
\hline lo11 Increasing my responsibility for English learning & 1 & 5 & 3.69 & 0.84 \\
\hline lo12 Increasing my English learning satisfaction & 1 & 5 & 3.68 & 0.79 \\
\hline
\end{tabular}

Regarding the correlation between learning motivation and learning outcomes, Table 6 shows there are significant correlations between the two sub-variables of learning motivation and the two sub-variables of learning outcomes at 0.01 level.

Table 6

Correlation between learning motivation and learning outcomes in blended learning

\begin{tabular}{lllll}
\hline & LM_1 & LM_2 & LO_1 & LO_2 \\
\hline LM_1 & 1 & & & \\
LM-2 & 0.06 & 1 & & \\
LO_1 & $0.33^{* *}$ & $0.12^{* *}$ & 1 & 1 \\
LO_2 & $0.46^{* *}$ & $0.10^{* *}$ & $0.60^{* *}$ & 1 \\
\hline
\end{tabular}

$* * p<0.01$.

Note. LM_1 = intrinsic learning motivation; LM_2 = extrinsic learning motivation; LO_1 = improvement in English linguistic competence; LO_2 = psychological development of English learning

\section{Structural equation modelling}

To examine the specific relationship between the students' learning motivation and learning outcomes within blended learning contexts, the path analysis was conducted using structural equation modelling. Figure 1 presents the structural pathways from students' learning motivation to learning outcomes. As shown in Table 7, the results of the goodness-of-fit measures reveal that the structural model has a good fit to the data $\left(\mathrm{x}^{2} / d f=2.967\right.$, normed fit index $(\mathrm{NFI})=0.939$, Tucker-Lewis index $(\mathrm{TLI})=0.948$, comparative fit index $(\mathrm{CFI})=0.959$, root mean square error of approximation $(\mathrm{RMSEA})=0.044)$. 


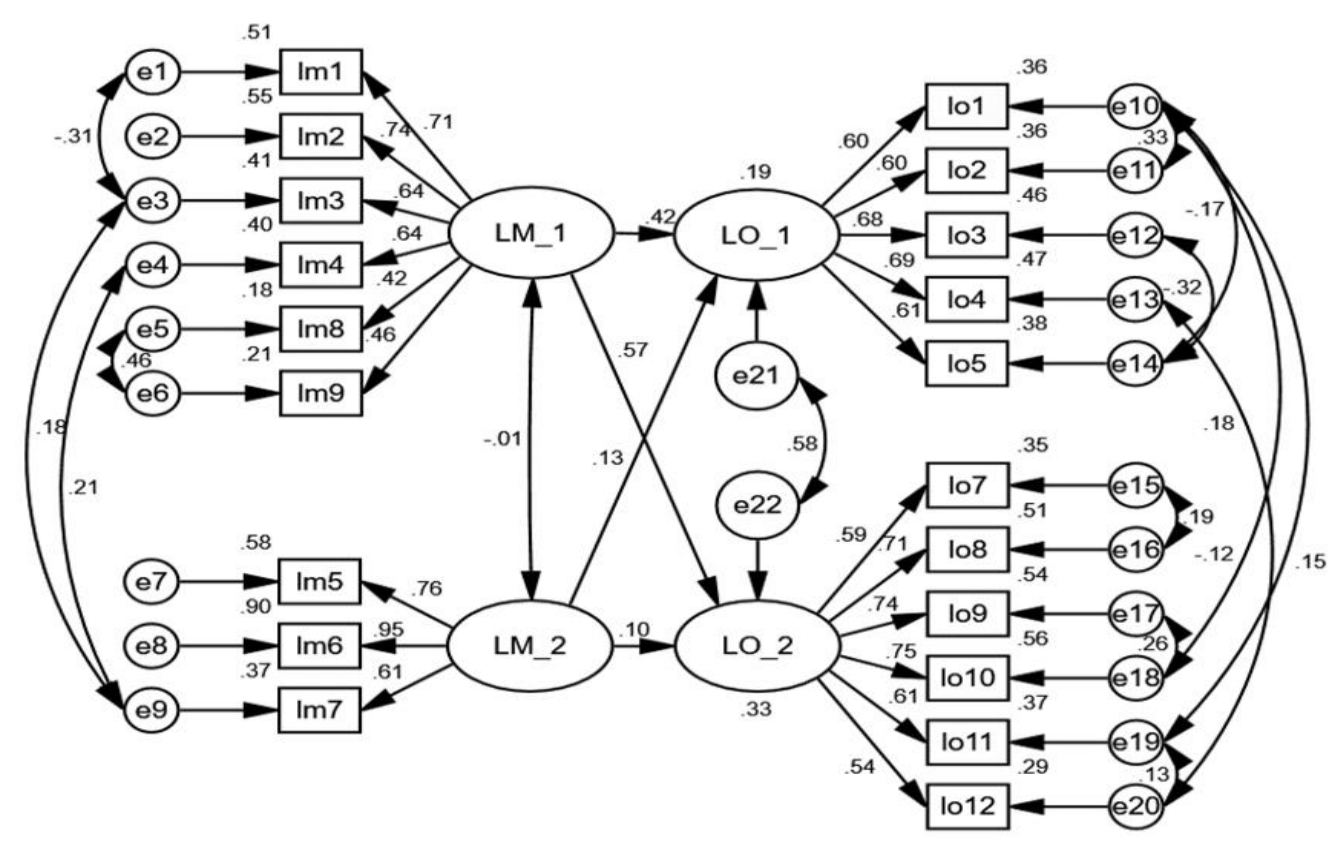

Figure 1. Structural equation model of pathways from learning motivation to learning outcomes

Table 7

Path analysis results model fit

\begin{tabular}{lcccccccc}
\hline & $\mathrm{x}^{2} / d f$ & NFI & TLI & CFI & GFI & AGFI & RMR & RMSEA \\
\hline $\begin{array}{l}\text { Threshold } \\
\text { value }\end{array}$ & $1-3$ & $>0.80$ & $>0.90$ & $>0.90$ & $>0.90$ & $>0.90$ & $<0.08$ & $<0.08$ \\
\begin{tabular}{l} 
Index value \\
\hline
\end{tabular} & 2.967 & 0.939 & 0.948 & 0.959 & 0.956 & 0.939 & 0.033 & 0.044 \\
\hline
\end{tabular}

As shown in Figure 1, the two factors of intrinsic learning motivation and extrinsic learning motivation are significant predictors of learning outcomes in blended learning. Intrinsic learning motivation has positive impacts on improvement in English linguistic competence $(\beta=0.42, p<.001)$ and psychological development of English learning $(\beta=0.57, p<.001)$. Likewise, extrinsic learning motivation has a significant positive relationship with improvement in English linguistic competence $(\beta=0.13, p<.001)$ and psychological development of English learning $(\beta=0.10, p<.001)$. Furthermore, intrinsic learning motivation can be explained by six pathways, with standard path coefficients ranging from 0.42 to 0.74 and significant at the 0.001 level; and therein the path coefficients of the two pathways of "having interest in English" and "understanding English culture" are significantly greater than other pathways. Extrinsic learning motivation can be reflected by three pathways (their standard path coefficients are $0.76,0.95,0.61$, respectively, with a significance level of 0.001 ), and the pathway from "getting good grades" to extrinsic learning motivation is the most influential and explanatory one. Additionally, improvement in English linguistic competence is explained by five pathways, and psychological development of English learning is reflected by six pathways, with path coefficients ranging from 0.54 to 0.75 ; all the estimates are significant at 0.001 level.

\section{Discussion}

\section{EFL students' learning motivation in a blended learning environment}

As shown through EFA (Table 3), EFL students' learning motivation in blended learning includes such intrinsic motivation as having interest in English, understanding English culture and socialising with foreigners, and extrinsic motivation as completing English curriculum tasks and finding a better job. According to descriptive analysis, the results indicate that students' extrinsic learning motivation is stronger than their intrinsic learning motivation (see Table 5). Yang's research (2018) drew similar conclusions that students majoring in English have stronger extrinsic motivation than intrinsic motivation. Moreover, during 
the interviews, when asked "What's your motivation for learning English?", seven out of 10 students mentioned that they learned English in order to pass exams and find jobs (see Table 1). According to the descriptive analysis, finding a better job is the top motive for learning English in blended learning contexts. This might result from the fact that college students are faced with great pressure in a tight job market, which can be evidenced from the interviews:

\begin{abstract}
Learning English is helpful for finding jobs in the future. Nowadays when graduates are looking for jobs, employers always attach great importance to their English language proficiency, such as passing College English Test Band 4, College English Test Band 6, IELTS, TOEFL and so on. Thus, we should try to improve our English in order to find a satisfactory job. (Student D)
\end{abstract}

I want to find a good job when I graduate. As learning English has become a mandatory skill for employees, I have to spend time and effort on it. Besides, College English is a compulsory course for us and I can't escape from it. (Student E)

\title{
EFL students' learning outcomes in a blended learning environment
}

Students' learning outcomes in blended learning involve two aspects: improvement in English linguistic competence and psychological development of English learning. On the one hand, blended learning facilitates students' listening, speaking, reading, writing and vocabulary development, which echoes previous research findings that implementing blended learning in language courses can significantly improve students' oral proficiency (Obari \& Lambacher, 2014; Wichadee, 2017), listening skills (H. R. Zhang et al., 2018), reading skills (Lungu, 2013) and writing knowledge and skills (Shih, 2011; Y. Y. Zheng, 2019) by employing Internet-based learning platforms (e.g., small private online courses, MOOCs, Edmodo) and social media tools such as Facebook and WordPress. On the other hand, EFL students' learning autonomy, confidence, perseverance and satisfaction are enhanced in a blended learning environment, which is consistent with research that students have greater autonomy in blended learning and they are satisfied with this particular learning model, which prompts greater student perseverance and confidence (Jia et al., 2012; López-Pérez et al., 2011; Pinto-Llorente et al., 2017; W. Zhang \& Han, 2012).

Furthermore, the results of the descriptive analysis indicate that students' English vocabulary improves the most in blended learning. This suggests that the blended learning model can substantially increase students' vocabulary knowledge by integrating online vocabulary assessment system with face-to-face teaching (Jia et al., 2012; Shams, 2013). Moreover, the results could be associated with students' learning habits. During the student interview, in response to the question "What methods do you often use to learn English outside the classroom and why do you use those methods?", most students favoured such vocabulary applications as Youdao Dictionary and BaiCizhan. Examples of responses follow:

When I encounter a new word in English learning, I often use Youdao Dictionary app to look up its meaning and usage. (Student $\mathrm{C}$ )

I memorise a list of words every day in BaiCizhan app to prepare myself for College English Test Band 6. (Student D)

Youdao Dictionary app is so convenient. Once you encounter new words, you can look them up in YouDao and add them to your vocabulary book. The app will automatically produce an appropriate plan for you to memorise these words and you will receive a notification that reminds you to finish your vocabulary tasks every day. (Student J)

\section{The relationship between learning motivation and learning outcomes in a blended learning environment}

The path analysis in Figure 1 shows that the path relations from the two factors of learning motivation (LM_1, LM_2) to the factors of learning outcomes (LO_1, LO_2) are significant, indicating that students' intrinsic motivation as well as extrinsic motivation are positively correlated with improvement in English linguistic competence and psychological development of English learning. This is in accordance with research findings that both are beneficial to successful language learning (Tokan \& Imakulata, 2019). 
Moreover, the results indicate that students' intrinsic learning motivation has a stronger positive impact on learning outcomes compared with extrinsic learning motivation. Accordingly, students who learn English out of interest with intrinsic goals of understanding English culture, socialising with foreigners and living abroad are more likely to improve their English linguistic competence and foster their psychological development of English learning in a blended learning environment. These findings resonate with Pae's (2008) argument that intrinsic motivation is the strongest determinant of students' learning confidence. According to Vansteenkiste et al. (2004), students who participate in learning activities with intrinsic goals are more dedicated and engaged than students participating for extrinsic factors, thus achieving higher levels of academic performance.

Among the six sub-pathways of intrinsic learning motivation, the two most important are having interest in English and understanding English culture. Students interested in English language and culture tend to be more attentive in self-regulated learning and are able to manage their classroom and web-based learning time efficiently in blended learning, as their intrinsic interest is closely linked to their self-regulation and time management (McWhaw \& Abrami, 2001; C. Zheng et al., 2018). Moreover, intrinsic interest has a long-term impact on students' learning behaviours and sustains their learning effort, promoting learner engagement during language learning (Gao et al., 2003; Lim \& Kim, 2003). Furthermore, the factor of understanding English culture is important for predicting students' improvement in English linguistic competence and their psychological development of English learning, for it motivates students to make contact with English cultural products during the English learning process, which further strengthens their interest in English language and culture (Gao et al., 2003).

In extrinsic learning motivation, the sub-pathway of getting good grades is the most significant predictor of learning outcomes. This may result from the fact that College English is a required course in Chinese universities and mastering English is regarded by students and their mediating agents, such as parents and teachers, as a crucial and preparatory stage for their future success (C. Zheng et al., 2018). Moreover, getting good grades is an immediate achievement, which impacts students' learning effort directly (Gao et al., 2003).

As discussed above, EFL students' intrinsic motivation (especially interest in English language and culture) plays a more important role than extrinsic motivation in promoting favourable learning outcomes within the context of blended learning. It empowers students to persist at learning tasks and achieve desired learning outcomes. However, the results of descriptive analysis of learning motivation suggest that Chinese EFL students' intrinsic motivation is not as strong as extrinsic motivation. Thus, the development of students' intrinsic motivation requires further attention, and foreign language educators need to adopt feasible strategies to enhance students' intrinsic curiosity and interest, such as game-based learning (Liu \& Chu, 2010), the combination of game theory approach with competition-based learning (Burguillo, 2017) and digital storytelling approach (Hung et al., 2012). Additionally, since indirect contact with cultural products affects students' cultural interest (Csizér \& Dörnyei, 2005), implementing authentic contextual cultural activities in blended language courses can be another effective way to foster students' intrinsic motivation, which could increase students' perception, curiosity and openness to the target language and culture (Byram et al., 2002).

\section{Conclusion}

The current study presents a systemic empirical examination of the relationship between Chinese EFL students' learning motivation and learning outcomes within the context of blended learning. Both intrinsic motivation and extrinsic motivation have a positive relationship with learning outcomes in blended learning, but the former is more influential and important than the latter. In intrinsic motivation, intrinsic interest in English and the intrinsic goal of understanding English culture are the two most significant predictors of learning outcomes.

By developing and testing a structural equation model to examine the relationship between students' learning motivation and learning outcomes, this study has practical and pedagogical implications for research on language learning motivation and blended learning and may serve as a reference for future research concerning learning motivation in blended learning contexts. Firstly, it reveals how different types of motivation affect learning outcomes within a blended learning environment. Secondly, it verifies the positive effect of both intrinsic and extrinsic motivation on learning outcomes and uncovers that students' 
intrinsic motivation is insufficient in a Chinese EFL learning context. Thirdly, it suggests the necessity of developing Chinese EFL students' intrinsic motivation in blended learning in order to produce more favourable learning outcomes. Finally, it is noteworthy that foreign language educators need to focus on the stimulation of students' intrinsic interest in foreign language and culture in terms of the development of intrinsic motivation in a blended learning environment.

However, the limitations of this study cannot be neglected. For one thing, the study was conducted in a specific context with EFL students in China; therefore, the findings may not be generalisable to other educational contexts. For another, the study collected students' perceptions of their learning motivation and learning outcomes, through a self-report questionnaire, which may ignore their actual learning performance. Thus, we suggest that future researchers devote more attention to students' blended learning process by conducting experimental studies or action research and gathering more qualitative data (such as observation of students' learning behaviours, student journals) so as to provide more sufficient evidence to verify the positive relationship between students' learning motivation and learning outcomes. Furthermore, how to develop students' intrinsic motivation to improve learning outcomes in blended learning is another direction for future research.

\section{Acknowledgements}

This work was supported by the Fundamental Research Funds for the Central Universities (Grant No. 2015AC001) and by the National Social Science Fund of China (Grant No.17BYY098).

\section{References}

Akgündüz, D., \& Akınoğlu, O. (2017). The impact of blended learning and social media-supported learning on the academic success and motivation of the students in science education. Education \& Science, 42(191), 69-90. https://doi.org/10.15390/EB.2017.6444

Burguillo, J. C. (2010). Using game theory and competition-based learning to stimulate student motivation and performance. Computers \& Education, 55(2), 566-575. https://doi.org/10.1016/j.compedu.2010.02.018

Byram, M., Gribkova, B., \& Starkey, H. (2002). Developing the intercultural dimension in language teaching: A practical introduction for teachers. Council of Europe. https://rm.coe.int/09000016802fc1c3

Carreira, J. M. (2011). Relationship between motivation for learning EFL and intrinsic motivation for learning in general among Japanese elementary school students. System, 39(1), 90-102. https://doi.org/10.1016/j.system.2011.01.009

Chen, K. C., \& Jang, S. J. (2010). Motivation in online learning: Testing a model of self-determination theory. Computers in Human Behavior, 26(4), 741-752. https://doi.org/10.1016/j.chb.2010.01.011

Ciampa, K. (2014). Learning in a mobile age: An investigation of student motivation. Journal of Computer Assisted Learning, 30(1), 82-96. https://doi.org/10.1111/jcal.12036

Crookes, G., \& Schmidt, R. W. (1991). Motivation: Reopening the research agenda. Language Learning, 41(4), 469-512. https://doi.org/10.1111/j.1467-1770.1991.tb00690.x

Csizér, K., \& Dörnyei, Z. (2005). The internal structure of language learning motivation and its relationship with language choice and learning effort. The Modern Language Journal, 89(1), 19-36. https://doi.org/10.1111/j.0026-7902.2005.00263.x

Deci, E. L., \& Ryan, R. M. (2008). Self-determination theory: A macrotheory of human motivation, development, and health. Canadian Psychology / Psychologie canadienne, 49(3), 182-185. https://doi.org/10.1037/a0012801

Deci, E. L., \& Ryan, R. M. (2012). Self-determination theory. In P. A. M. Van Lange, A. W. Kruglanski, \& E. T. Higgins (Eds.), Handbook of theories of social psychology (pp. 416-437). Sage Publications Ltd. https://doi.org/10.4135/9781446249215.n21

Fırat, M., Kılınç, H., \& Yüzer, T. V. (2018). Level of intrinsic motivation of distance education students in e-learning environments. Journal of Computer Assisted Learning, 34(1), 63-70.

https://doi.org/10.1111/jcal.12214 
Gao, Y. H., Cheng, Y., Zhao, Y., \& Zhou, Y. (2003). 英语学习动机类型与动机强度的关系一对大学 本科生的定量考察 [The relationship between types of English learning motivation and motivational intensity: A quantitative investigation on Chinese college undergraduates]. Foreign Languages Research, 1, 60-80.

Gardner, R. C. (1985). Social psychology and second language learning: The role of attitude and motivation. Edward Arnold Ltd.

Garrison, D. R., \& Kanuka, H. (2004). Blended learning: Uncovering its transformative potential in higher education. Internet and Higher Education, 7(2), 95-105. https://doi.org/10.1016/j.iheduc.2004.02.001

Graham, C. R. (2012). Blended learning systems: Definition, current trends, and future directions. In C. J. Bonk \& C. R. Graham (Eds.), The handbook of blended learning: Global perspectives, local designs (pp. 3-21). Pfeiffer Publishing.

He, K. K. (2004). 从Blending Learning看教育技术理论的新发展(下) [The new development of educational technological theories from the perspective of blended learning]. China Educational Technology, 4, 10-15.

Hsieh, T. (2014). Motivation matters? The relationship among different types of learning motivation, engagement behaviors and learning outcomes of undergraduate students in Taiwan. Higher Education, 68(3), 417-433. https://doi.org/10.1007/s10734-014-9720-6

Hung, C., Hwang, G., \& Huang, I. (2012). A project-based digital storytelling approach for improving students' learning motivation, problem-solving competence and learning achievement. Journal of Educational Technology \& Society, 15(4), 368-379. https://drive.google.com/open?id=11MCW5ZVjqeNhsCJWPfCb_LWsZ1AnbObF

Ituma, A. (2011). An evaluation of students' perceptions and engagement with e-learning components in a campus based university. Active Learning in Higher Education, 12(1), 57-68. https://doi.org/10.1177\%2F1469787410387722

Jia, J., Chen, Y., Ding, Z., \& Ruan, M. (2012). Effects of a vocabulary acquisition and assessment system on students' performance in a blended learning class for English subject. Computers \& Education, 58(1), 63-76. https://doi.org/10.1016/j.compedu.2011.08.002

Kofar, G. (2016). A study of EFL instructors' perceptions of blended learning. Procedia - Social and Behavioral Sciences, 232, 736-744. https://doi.org/10.1016/j.sbspro.2016.10.100

Law, K. M., Lee, V. C., \& Yu, Y. T. (2010). Learning motivation in e-learning facilitated computer programming courses. Computers \& Education, 55(1), 218-228. https://doi.org/10.1016/j.compedu.2010.01.007

Lim, D. H., \& Kim, H. (2003). Motivation and learner characteristics affecting online learning and learning application. Journal of Educational Technology Systems, 31(4), 423-439. https://doi.org/10.2190\%2F0LW0-KE8X-MDYH-X27F

Lim, D. H., \& Morris, M. L. (2009). Learner and instructional factors influencing learning outcomes within a blended learning environment. Journal of Educational Technology \& Society, 12(4), 282293. https://drive.google.com/open?id=1o2-qRDp51_u1G2IJEebdqIbQyb34i_AF

Liu, T., \& Chu, Y. (2010). Using ubiquitous games in an English listening and speaking course: Impact on learning outcomes and motivation. Computers \& Education, 55(2), 630-643. https://doi.org/10.1016/j.compedu.2010.02.023

López-Pérez, M. V., Pérez-López, M. C., \& Rodríguez-Ariza, L. (2011). Blended learning in higher education: Students' perceptions and their relation to outcomes. Computers \& Education, 56(3), 818826. https://doi.org/10.1016/j.compedu.2010.10.023

Lungu, I. (2013). The increasing need for blended-learning models in courses of English for specific courses in Romanian universities. Procedia - Social and Behavioral Sciences, 76, 470-475. https://doi.org/10.1016/j.sbspro.2013.04.148

Ma, W. L., \& Zhang, X. P. (2011). 大学英语混合式学习模式研究与实践 [Research and practice on college English blended learning model]. Computer-assisted Foreign Language Education, (3), 5057.

McWhaw, K., \& Abrami, P. C. (2001). Student goal orientation and interest: Effects on students' use of self-regulated learning strategies. Contemporary Educational Psychology, 26(3), 311-329. https://doi.org/10.1006/ceps.2000.1054 
Obari, H., \& Lambacher, S. (2014). Impact of a blended environment with m-learning on EFL skills. In S. Jager, L. Bradley, E. J. Meima, \& S. Thouësny (Eds.), CALL design: Principles and practiceProceedings of the 2014 EUROCALL Conference, Groningen, The Netherlands (pp. 267-272). Research-publishing.net. https://doi.org/10.14705/rpnet.2014.000229

Pae, T. (2008). Second language orientation and self-determination theory: A structural analysis of the factors affecting second language achievement. Journal of Language and Social Psychology, 27(1), 5-27. https://doi.org/10.1177/0261927X07309509

Pereira, J. A., Pleguezuelos, E., Merí, A., Molina-Ros, A., Molina-Tomás, M. C., \& Masdeu, C. (2007). Effectiveness of using blended learning strategies for teaching and learning human anatomy. Medical Education, 41(2), 189-195. https://doi.org/10.1111/j.1365-2929.2006.02672.x

Pinto-Llorente, A. M., Sánchez-Gómez, M. C., García-Peñalvo, F. J., \& Casillas-Martín, S. (2017). Students' perceptions and attitudes towards asynchronous technological tools in blended-learning training to improve grammatical competence in English as a second language. Computers in Human Behavior, 72, 632-643. https://doi.org/10.1016/j.chb.2016.05.071

Ryan, R. M., \& Deci, E. L. (2020). Intrinsic and extrinsic motivation from a self-determination theory perspective: Definitions, theory, practices, and future directions. Contemporary Educational Psychology, 61, Article 101860. https://doi.org/10.1016/j.cedpsych.2020.101860

Saito, K., Dewaele, J., \& Hanzawa, K. (2016). A longitudinal investigation of the relationship between Motivation and late second language speech learning in classroom settings. Language and Speech, 60(4), 614-632. https://doi.org/10.1177/0023830916687793

Shams, I. E. (2013). Hybrid learning and Iranian EFL learners' autonomy in vocabulary learning. Procedia - Social and Behavioral Sciences, 93, 1587-1592. https://doi.org/10.1016/j.sbspro.2013.10.086

Shih, R. C. (2011). Can Web 2.0 technology assist college students in learning English writing? Integrating Facebook and peer assessment with blended learning. Australasian Journal of Educational Technology, 27(5), 829-845. https://doi.org/10.14742/ajet.934

So, H., \& Brush, T. A. (2008). Student perceptions of collaborative learning, social presence and satisfaction in a blended learning environment: Relationships and critical factors. Computers \& Education, 51(1), 318-336. https://doi.org/10.1016/j.compedu.2007.05.009

Su, C. H., \& Cheng, C. H. (2015). A mobile gamification learning system for improving the learning motivation and achievements. Journal of Computer Assisted Learning, 31, 268-286. https://doi.org/10.1111/jcal.12088

Suo, G. F., \& Chi, R. B. (2018). 基于慕课的混合式跨文化外语教学研究 [A study on the MOOCsbased blended intercultural foreign language teaching]. Foreign Language World, 3, 89-96.

Tokan, M. K., \& Imakulata, M. M. (2019). The effect of motivation and learning behaviour on student achievement. South African Journal of Education, 39(1), 1-8. https://doi.org/10.15700/saje.v39n1a1510

Tosun, S. (2015). The effects of blended learning on EFL students' vocabulary enhancement. Procedia Social and Behavioral Sciences, 199, 641-647. https://doi.org/10.1016/j.sbspro.2015.07.592

Vanslambrouck, S., Zhu, C., Lombaerts, K., Philipsen, B., \& Tondeur, J. (2018). Students' motivation and subjective task value of participating in online and blended learning environments. The Internet and Higher Education, 36, 33-40. https://doi.org/10.1016/j.iheduc.2017.09. 002

Vansteenkiste, M., Simons, J., Lens, W., Sheldon, K. M., \& Deci, E. L. (2004). Motivating learning, performance, and persistence: The synergistic effects of intrinsic goal contents and autonomysupportive contexts. Journal of Personality and Social Psychology, 87(2), 246-260. https://doi.apa.org/doi/10.1037/0022-3514.87.2.246

Wang, M., Shen, R., Novak, D., \& Pan, X. (2009). The impact of mobile learning on students' learning behaviours and performance: Report from a large blended classroom. British Journal of Educational Technology, 40(4), 673-695. https://doi.org/10.1111/j.1467-8535.2008.00846.x

Wichadee, S. (2017). A development of the blended learning model using Edmodo for maximizing students' oral proficiency and motivation. International Journal of Emerging Technologies in Learning, 12(2), 137-154. https://doi.org/10.3991/ijet.v12i02.6324

Wu, J. H., Tennyson, R. D., \& Hsia, T. L. (2010). A study of student satisfaction in a blended e-learning system environment. Computers \& Education, 55, 155-164. https://doi.org/10.1016/j.compedu.2009.12.012

$\mathrm{Wu}, \mathrm{L}$. F. (2013). Learners' perceptions of a blended English learning program in Taiwan. Asian Journal of Distance Education, 11(2), 4-13. https://www.learntechlib.org/p/185239/ 
Yang, M. (2018). Learning motivation among university English-language majors under hierarchical teaching model. Educational Sciences: Theory \& Practice, 18(6), 3543-3549. https://doi.org/10.12738/estp.2018.6.265

Yilmaz, R. (2017). Exploring the role of e-learning readiness on student satisfaction and motivation in flipped classroom. Computers in Human Behavior, 70, 251-260. https://doi.org/10.1016/j.chb.2016.12.085

Yusoff, S., Yusoff, R., \& Noh, N. H. M. (2017). Blended learning approach for less proficient students. SAGE Open, 7(3), 1-8. https://doi.org/10.1177/2158244017723051

Zhang, H. R., Yang, F., \& Zhang, W. X. (2018). 基于MOOC的混合式教学设计与实践一以 “基础英 语听说” 课程为例 [Instructional design and teaching practice of blended learning based on MOOC: In the case of basic English listening and speaking course]. Modern Educational Technology, 12, 6267.

Zhang, W., \& Han, C. (2012). A case study of the application of a blended learning approach to webbased college English teaching platform in a medical university in eastern China. Theory and Practice in Language Studies, 2(9), 1961-1970. http://www.academypublication.com/issues/past/tpls/vol02/09/27.pdf

Zhang, Y. L. (2013). 基于BL和CL理论的大学英语一体化学习模式实验研究 [An experimental study on an integrative learning approach to college English teaching based on BL and CL theories]. Computer-Assisted Foreign Language Education, (5), 16-24.

Zheng, C., Liang, J., Li, M., \& Tsai, C. (2018). The relationship between English language learners' motivation and online self-regulation: A structural equation modelling approach. System, 76, 144-157. https://doi.org/10.1016/j.system.2018.05.003

Zheng, Y. Y. (2019). SPOC混合式教学在英语学术写作课堂中的促学效果研究 [A study of the learning effects of a SPOC blended English academic writing course]. Technology Enhanced Foreign Language Education, (5), 50-55.

Corresponding author: Renzhong Peng, pengrz@ hust.edu.cn

Copyright: Articles published in the Australasian Journal of Educational Technology (AJET) are available under Creative Commons Attribution Non-Commercial No Derivatives Licence (CC BYNC-ND 4.0). Authors retain copyright in their work and grant AJET right of first publication under CC BY-NC-ND 4.0.

Please cite as: Peng, R., \& Fu, R. (2021). The effect of Chinese EFL students' learning motivation on learning outcomes within a blended learning environment. Australasian Journal of Educational Technology, 37(4), 61-74. https://doi.org/10.14742/ajet.6235 